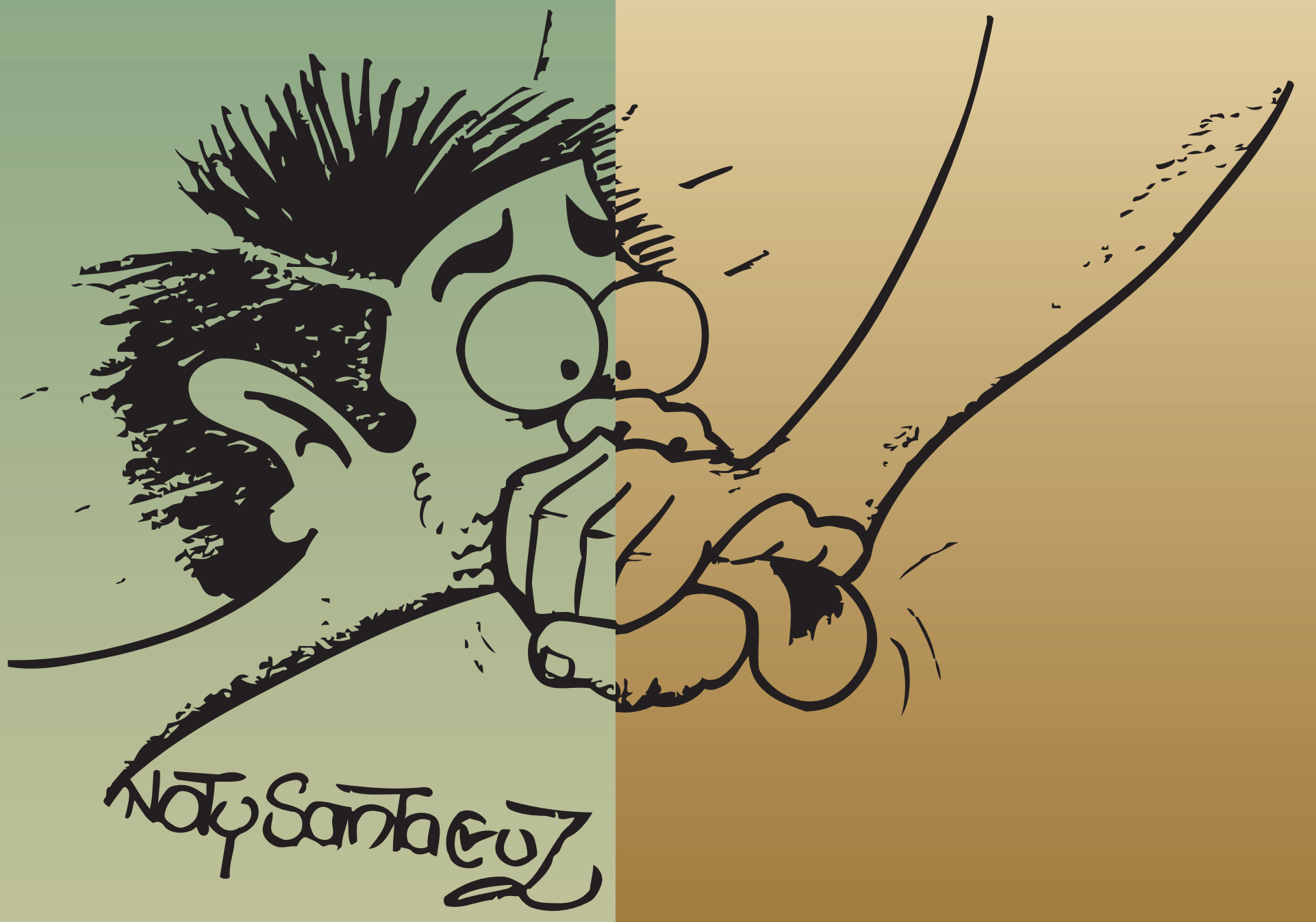

Palabra de autor 


\section{Derechos \\ humanos y \\ derecho a la \\ comunicación}

\section{Fernando Chamorro Garcés}

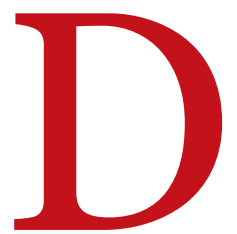

os temas son inherentes a los derechos humanos: la dignidad y la libertad. La dignidad es una característica propia de los seres humanos y aunque es un término cuya definición no resulta fácil, se lo asocia con ciertas características que identifican la existencia humana y se relacionan con su individualidad y su particular forma de sociabilidad. Para algunos filósofos, como Kant, la dignidad humana deriva de su naturaleza racional, atributo exclusivo de las personas. A nadie se le ocurriría hablar de un mueble digno o de la dignidad de una hormiga o una termita.

La dignidad pertenece a lo más profundo del ser humano, de allí que puede tratarse de un individuo cuya conducta sea reprochable, inclusive un delincuente, y sin embargo no podrá despojársele de su carácter intrínseco de "ser digno". Deberá ser tratado siempre como persona. 
1 Fernandez-Armesto, Felipe. Breve Historia de la Humanidad. Ediciones B. Barcelona, 2005. p. 22
La dignidad se convierte entonces en un sustento fundamental de los derechos humanos, ya que se relaciona con el ser más íntimo, puesto de manifiesto en la capacidad de autoconciencia, propia de los seres humanos, únicos capaces de pensarse a sí mismos y proponer una visión prospectiva de su vida.

En cuanto a la libertad, nos referimos a esa responsabilidad que nos permite actuar como nuestra conciencia nos dicta, en el marco de las normas jurídicas y de comportamiento que rigen un momento y sociedad determinados. Para ello hacemos uso de nuestra capacidad de querer y entender, así hablamos de la libertad de conciencia, de cultos, de expresión, de comercio, etc.

Estos dos elementos, fundamentales para una adecuada valoración de los derechos humanos, tienen importancia particular cuando tratamos del derecho a la comunicación.

La comunicación, cuya manifestación externa es el lenguaje, ha logrado su forma más elaborada en los seres humanos. Esta aclaración es necesaria pues ciertos etólogos atribuyen también dicha capacidad, aunque en menor grado, a otras especies. Inclusive Felipe Fernández-Armesto, actual profesor de historia de la Universidad de Londres, en un interesante libro titulado "Breve Historia de la Humanidad", afirma que "a menos que la disposición al lenguaje constituya un poder especial de la mente, fuera de toda explicación, en princi- pio deberá ser accesible a más de una especie; en efecto, el desconocimiento de los métodos que emplean especies no humanas para expresarse y comunicarse torna dudosos los asertos sobre la singularidad humana”. ${ }^{1}$

En su versión etimológica comunicación viene de communicare, "intercambiar, compartir, poner en común", a su vez del latín antiguo comoinis y éste del indoeuropeo ko-moin-i "común, público"; que deriva de ko"juntamente" + moi-n "intercambio de servicios". Sería una forma de comunión, y constituye el proceso mediante el cual podemos transmitir al otro lo que sabemos o sentimos. La comunicación humana constituye esa capacidad para elaborar mensajes y transferirlos a nuestros semejantes a través de los mecanismos más diversos. No olvidemos que, según ciertos especialistas, el lenguaje gestual en los seres humanos constituye hasta el 70\% de las maneras de comunicarnos. Quizá por ello a menudo afirmamos que más se dice con un gesto que con muchas palabras. Tampoco podemos menospreciar los recursos utilizados por las personas ciegas y los sordomudos que tienen en el Braille o el lenguaje de signos formas válidas para manifestar sus pensamientos.

Por ello la comunicación humana, ese producto de una mente racional que nos permite transferir a otros nuestros anhelos, esperanzas, abstracciones y conocimientos, constituye un derecho singular que históricamente ha sido valorado en toda sociedad libre.

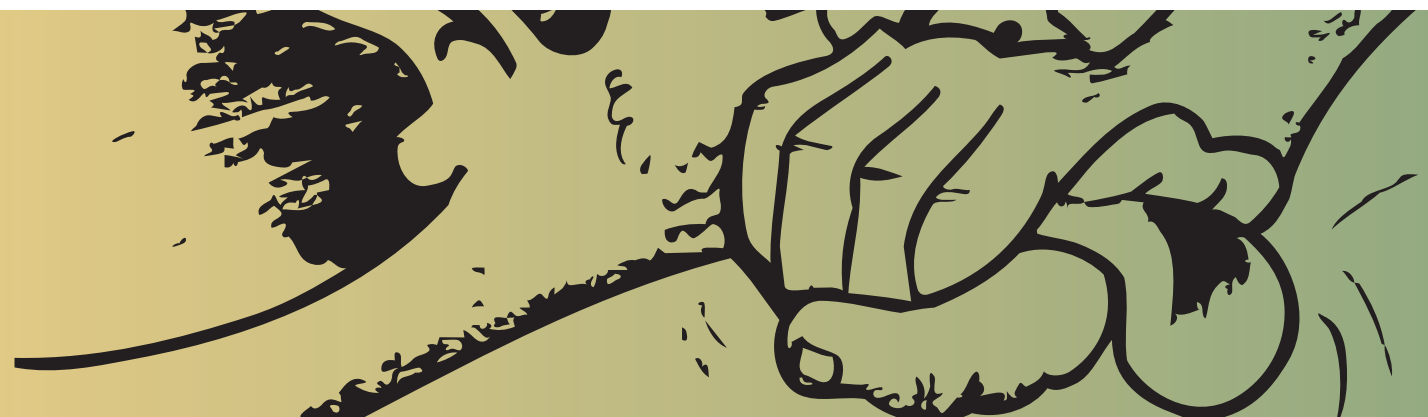




\section{Universalidad de los derechos humanos}

Para tratar de los derechos humanos conviene mencionar la discusión actual que plantea ciertas dudas sobre su condición de universalidad. En varios instrumentos internacionales, particularmente la Declaración y el Programa de Acción de Viena de 1993, se insta al respeto por todos los países de los tratados de derechos humanos. Así se anota: "I.5. Todos los derechos humanos son universales, indivisibles e interdependientes y están relacionados entre sí. La comunidad internacional debe tratar los derechos humanos de manera global y de manera justa y equitativa, en pie de igualdad y dándoles a todos el mismo peso... los Estados tienen el deber, sea cuales fueren sus sistemas políticos, económicos y culturales, de promover y proteger todos los derechos humanos y las libertades fundamentales".

"I.26. La Conferencia Mundial de Derechos Humanos celebra el progreso alcanzado en la codificación de los instrumentos de derechos humanos, que constituye un proceso dinámico y evolutivo, e insta a la ratificación universal de los tratados de derechos humanos".

\section{Pero, ¿pueden considerarse universales los derechos humanos?}

Varios especialistas, especialmente orientales, consideran que el conjunto de normas internacionales que rige actualmente esta materia constituye una imposición occidental, consecuencia de la hegemonía que han tenido sus ideas en los tiempos modernos. Se afirma que los derechos humanos aíslan al ser humano de su entorno vital, del mundo animal y vegetal, de su cosmología, así como de las dimensiones social y política que son propias de su naturaleza. Son normas que valoran al ser humano individual, arrogantemente convertido en la cúspide de todo, pues aspira a que se conserven sin límites sus "derechos naturales e imprescriptibles". Ni siquiera la familia es incorporada claramente en esa concepción, ya que se desconoce su rol fundamental en la mediación entre el individuo y la sociedad.

Ciertos pueblos del mundo, particularmente la India y China, pero también africanos y de nuestras comunidades ancestrales, asumen que el hombre no puede concebirse como un ser aislado frente a la naturaleza y específicamente los animales. De alguna forma este criterio ha sido incorporado en la Constitución ecuatoriana de 2008 que plantea los "Derechos de la naturaleza y del buen vivir". Así, en el artículo 71, se dice: "La naturaleza o Pacha Mama donde se reproduce y realiza la vida, tiene derecho a que se respete integralmente su existencia y el mantenimiento y regeneración de sus ciclos vitales, estructura, funciones y procesos evolutivos". En concordancia con esto, en el artículo 14, "Se reconoce el derecho de la población a vivir en un ambiente sano y ecológicamente equilibrado, que garantice la sostenibilidad y el buen vivir, sumak kawsay"s.

Sociedades como la hindú mantienen una relación con la muerte ajena a nosotros, pues aceptan la reencarnación en los animales que pasan a ser parte de la vida considerada un conjunto único, expresión de esa unidad indivisible de toda forma de existencia.

Esto nos llevaría a pensar que las explicaciones puramente ideológicas que justifican la universalidad de los derechos humanos resultan insuficientes. Según el
2 Declaración y

Programa de Acción de

Viena. Anexo VI de la

obra Manual de

Derechos Humanos de

Pedro Pablo Camargo.

Editorial Leyes, Bogotá,

1995. p. 452.

3 Constitución Política del Ecuador, 2008.

Editorial Universitaria,

Universidad Central del

Ecuador. Quito, sep-

tiembre, 2008.

4 Citado por François Jullien. Universels, les droits de l'homme? Le Monde diplomatique. París, febrero de 2008. 
filósofo francés François Jullien la única justificación aceptable de los derechos humanos podría sustentarse en un ejemplo chino según el cual una persona observa a un niño a punto de caer a un pozo y, de inmediato, presa de pánico, hace un gesto para detenerlo (no porque tenga una relación particular con sus padres, quiera ser reconocido por su mérito o tenga recelo de ser cuestionado); se trata de un gesto espontáneo, una simple reacción instintiva que no puede dejar de tener. Según el filósofo chino Mencio "quien no tiene esa conciencia de la piedad no es un hombre"4

Los derechos humanos serían entonces universales, no tanto como expresión de la cultura occidental, sino como manifestación de ese mecanismo universal de rechazo ante la falta de una reacción incontrolable frente al daño, que debe caracterizar al ser humano. Esa actitud sí tendría vocación universal.

\section{El derecho a la comunicación}

Si un distintivo esencial del ser humano es la racionalidad, significa que poseemos conciencia lúcida de nuestras motivaciones e intenciones, lo que nos induce a la búsqueda de libertad, o al menos a la ilusión de poseerla. Los seres que actúan de manera puramente instintiva, por carecer de libre albedrío, no reparan en lo que significa perder la libertad de expresión, aunque quizá tampoco la necesiten.

Históricamente el control del pensamiento ha sido una constante en toda tendencia unívoca, vindicativa e intelectualmente exterminadora. Su expresión práctica se da en el control de la libertad de comunicar o expresarse, forma de comportamiento frecuente cuando las propuestas del otro se convierten en peligrosas, pues cuestionan esa visión unilateral de la realidad que poseen algunos.

La humanidad está llena de ejemplos de censura y castigo por motivos de orden político, religioso o moral. Así aparece la crueldad de Cornelio Sila, Calígula o Nerón, cuyos contradictores terminaron envenenados o decapitados. La severa represión de la Edad Media y sus sofisticados mecanismos contra la herejía, cuyo ejemplo más evidente son los procesos de Giordano Bruno y Galileo Galilei, o los casos más próximos de intolerancia con Hitler, Stalin, Duvalier, Pol Pot, Videla o Pinochet.

Todos ellos hicieron de la represión del pensamiento su principal mecanismo para gobernar. Quien se cree imbuido por esa suerte de mesianismo necesita coartar el uso de la razón y limitar al máximo las posibilidades de expresión de quienes no se ajustan a su patrón de pensamiento.

Las modernas libertades del ser humano en materia de opinión, expresión e información están íntimamente relacionadas con la libertad de prensa y de imprenta. Dichas libertades involucran tanto a quienes producen el mensaje como a

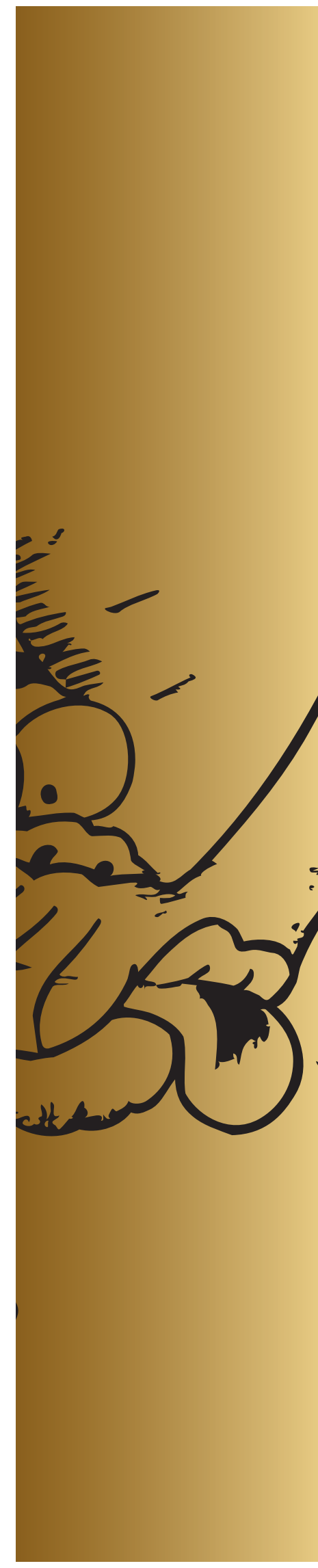


quienes lo reciben, lo cual hace necesario fijar ciertos parámetros que consideren los derechos y obligaciones de cada uno de los actores.

El derecho a la comunicación tiene intereses diversos, pues involucra tanto los derechos de quienes se encargan de transmitir mensajes a través de los mecanismos más diversos (desde los tradicionales periódicos, radio y televisión, hasta los modernos relacionados con el espectro radioeléctrico y su vasta gama de nuevas tecnologías de la comunicación), como las garantías de los sujetos que reciben tales mensajes. Esta concepción amplia del derecho a la comunicación debería permitirnos conciliar posiciones que a menudo son antagónicas, y hacerlo de manera transparente, sin limitaciones, como un adecuado ejercicio que ayude a consolidar la democracia.

Una postura de esta naturaleza reconoce que la libertad de pensamiento, opinión y expresión son propias de toda persona individualmente considerada, y que el Estado no solamente está obligado a no coartarla, sino que debe contribuir para que pueda ejercitarse a plenitud.

No obstante, si lo vemos desde la óptica del "derecho a la información" que tenemos todos los habitantes, le corresponderá también al Estado estimular las condiciones para que éste pueda ejercitarse sin otras limitaciones que no sean el respeto de las normas jurídicas que regulan otras libertades, como la individual, la de cultos, políticas, etc.

\section{Derecho a la comunicación y derechos humanos}

La historia de los derechos humanos es vasta y diversa. Algunos autores la identifican ya con principios defendidos por Mencio en China, o por el pueblo griego, como cuando Antígona reclama el derecho a que se respete la dignidad del cadáver de su hermano, que no podía ser enterrado por decisión de su enemigo, el rey Creonte.

No obstante, existe un consenso al admitir que el sistema universal de protección de los derechos humanos se consolida de manera irreversible luego de la segunda guerra mundial, mediante la Declaración Universal de Derechos Humanos, adoptada y proclamada el 10 de diciembre de 1948. Nunca antes un instrumento jurídico no vinculante tuvo la trascendencia de dicha Declaración, convertida ya en el más importante referente moral de la humanidad contemporánea.

Para asegurar la obligatoriedad de los Estados que no se había logrado inicialmente, pues se aprobó solamente una Declaración y no un Tratado o Protocolo, han ido promulgándose múltiples instrumentos internacionales que consolidan jurídicamente esa preocupación por el respeto de la libertad y dignidad de todos. 
5. Citado en la obra "Los Derechos de la Comunicación". INREDH, Quito, 2004. p. 110
Un conjunto de normas tan amplio condujo a la creación de diversos organismos del sistema de las Naciones Unidas dedicados a cada materia. Tanto la Organización de las Naciones Unidas para la Educación, la Ciencia y la Cultura, UNESCO, como el Comité de Derechos Humanos o el Alto Comisionado para los Derechos Humanos, junto con organismos dedicados a temas de particular preocupación como la lucha contra la discriminación racial, contra la tortura y las demás formas de trato cruel, inhumano y degradante, los derechos de la mujer y del niño, la situación de los refugiados, etc., son muestra de esa preocupación por la plena vigencia de los derechos humanos. Entre ellos el tema de la libertad de expresión ha tenido un interés relevante.

Paralelo al sistema universal han surgido formas regionales de protección y, para América, ha ido perfeccionándose un Sistema Interamericano de los Derechos Humanos en el marco de la Organización de los Estados Americanos.

Así, la Comisión Interamericana de los Derechos Humanos, creada en 1960, y posteriormente la Corte Interamericana de 1978, constituyen avances de un sistema regional que en ciertos aspectos ha sido pionero en la defensa teórica, aunque no siempre en la protección real de los derechos humanos.

Si nos referimos al sistema universal de los derechos humanos, la Declaración Universal establece:

"Art. 19. Todo individuo tiene derecho a la libertad de opinión y de expresión; este derecho incluye el de no ser molestado a causa de sus opiniones, el de investigar y recibir informacio- nes y opiniones, $y$ el de difundirlas, sin limitación de fronteras, por cualquier medio de expresión”.

De igual forma, el Pacto

Internacional de Derechos Civiles y Políticos señala:

"Art. 19.

1. Nadie podrá ser molestado a causa de sus opiniones.

2. Toda persona tiene derecho a la libertad de expresión; este derecho comprende la libertad de buscar, recibir $y$ difundir informaciones $e$ ideas de toda índole, sin consideración de fronteras, ya sea oralmente, por escrito o en forma impresa o artística, o por cualquier otro procedimiento de su elección.

3. El ejercicio del derecho previsto en el párrafo 2 de este artículo entrana deberes y responsabilidades especiales. Por consiguiente, puede estar sujeto a ciertas restricciones, que deberán, sin embargo, estar expresamente fijadas por la ley $y$ ser necesarias para:

a) Asegurar el respeto a los derechos o a la reputación de los demás;

b) La protección de la seguridad nacional, el orden público o la salud o la moral públicas".

La libertad de expresión es uno de los derechos reconocidos más ampliamente por las Constituciones Políticas en el mundo pues, según Ernesto Villanueva $^{5}$, se halla en las cartas fundamentales de 178 países, esto es, en el 94\% de los estados existentes.

En cuanto al sistema interamericano, la Declaración Americana de los Derechos y Deberes del Hombre, de 1948, establece: 
"Art. IV. Toda persona tiene derecho a la libertad de investigación, de opinión y de expresión y difusión del pensamiento por cualquier medio"

De otra parte, la Convención Interamericana de Derechos Humanos señala:

\section{“Art. 13. Libertad de Pensamiento y de Expresión}

1. Toda persona tiene derecho a la libertad de pensamiento y de expresión. Este derecho comprende la libertad de buscar, recibir y difundir informaciones $e$ ideas de toda índole, sin consideraciones de fronteras, ya sea oralmente, por escrito o en forma impresa o artística, o por cualquier otro procedimiento de su elección.

2. El ejercicio del derecho previsto en el inciso precedente no puede estar sujeto a previa censura sino a responsabilidades ulteriores, las que deben estar expresamente fijadas por la ley y ser necesarias para asegurar:

a) el respeto a los derechos o a la reputación de los demás, o

b) la protección de la seguridad nacional, el orden público o la salud o la moral públicas.

No se puede restringir el derecho de expresión por vías o medios indirectos, tales como el abuso de controles oficiales o particulares de papel para periódicos, de frecuencias radioeléctricas, o de enseres y aparatos usados en la difusión de información o por cualesquiera otros medios encaminados a impedir la comunicación y la circulación de ideas y opiniones"

Sobre este tema adquiere singular importancia el contenido de la Declaración de Principios sobre Libertad de Expresión de la Comisión Interamericana de Derechos Humanos que establece lo siguiente:

"1. La libertad de expresión, en todas sus formas y manifestaciones, es un derecho fundamental e inalienable, inherente a todas las personas. Es, además, un requisito indispensable para la existencia misma de una sociedad democrática.

2. Toda persona tiene el derecho a buscar, recibir y difundir información y opiniones libremente en los términos que estipula el artículo 13 de la Convención Americana sobre Derechos Humanos. Todas las personas deben contar con igualdad de oportunidades para recibir, buscar e impartir información por cualquier medio de comunicación sin discriminación, por ningún motivo, inclusive los de raza, color, religión, sexo, idioma, opiniones políticas o de cualquier otra índole, origen nacional o social, posición económica, nacimiento o cualquier otra condición social.

5. La censura previa, interferencia o presión directa o indirecta sobre cualquier expresión, opinión o información difundida a través de cualquier medio de comunicación oral, escrito, artístico, visual o electrónico, debe estar prohibida por la ley. Las restricciones en la circulación libre de ideas y opiniones, como así también la imposición arbitraria de información y la creación de obstáculos al libre flujo informativo, violan el derecho a la libertad de expresión.

7. Condicionamientos previos, tales como veracidad, oportunidad o imparcialidad por parte de los Estados son incompatibles con el derecho a la libertad de expresión reconocido en los instrumentos internacionales. 
8. Todo comunicador social tiene derecho a la reserva de sus fuentes de información, apuntes y archivos personales y profesionales.

10. Las leyes de privacidad no deben inhibir ni restringir la investigación y difusión de información de interés público. La protección a la reputación debe estar garantizada sólo a través de sanciones civiles, en los casos en que la persona ofendida sea un funcionario público o persona pública o particular que se haya involucrado voluntariamente en asuntos de interés público. Además, en estos casos, debe probarse que en la difusión de las noticias el comunicador tuvo intención de infligir daño o pleno conocimiento de que se estaba difundiendo noticias falsas o se condujo con manifiesta negligencia en la búsqueda de la verdad o falsedad de las mismas.

11. Los funcionarios públicos están sujetos a un mayor escrutinio por parte de la sociedad. Las leyes que penalizan la expresión ofensiva dirigida a funcionarios públicos generalmente conocidas como "leyes de desacato" atentan contra la libertad de expresión y el derecho a la información.

12. Los monopolios u oligopolios en la propiedad y control de los medios de comunicación deben estar sujetos a leyes antimonopólicas por cuanto conspiran contra la democracia al restringir la pluralidad y diversidad que asegura el pleno ejercicio del derecho a la información de los ciudadanos. En ningún caso esas leyes deben ser exclusivas para los medios de comunicación. Las asignaciones de radio y televisión deben considerar criterios democráticos que garanticen una igualdad de oportunidades para todos los individuos en el acceso a los mismos.

13. La utilización del poder del Estado y los recursos de la hacienda pública; la concesión de prebendas arancelarias; la asignación arbitraria y discriminatoria de publicidad oficial y créditos oficiales; el otorgamiento de frecuencias de radio y televisión, entre otros, con el objetivo de presionar y castigar o premiar y privilegiar a los comunicadores sociales y a los medios de comunicación en función de sus líneas informativas, atenta contra la libertad de expresión y deben estar expresamente prohibidos por la ley. Los medios de comunicación social tienen derecho a realizar su labor en forma independiente. Presiones directas o indirectas dirigidas a silenciar la labor informativa de los comunicadores sociales son incompatibles con la libertad de expresión".

En el Ecuador, la Constitución vigente señala a este respecto:

"Art. 16.- Todas las personas, en forma individual o colectiva tienen derecho a:

1. Una comunicación libre, intercultural, incluyente, diversa y participativa, en todos los ámbitos de la inter-

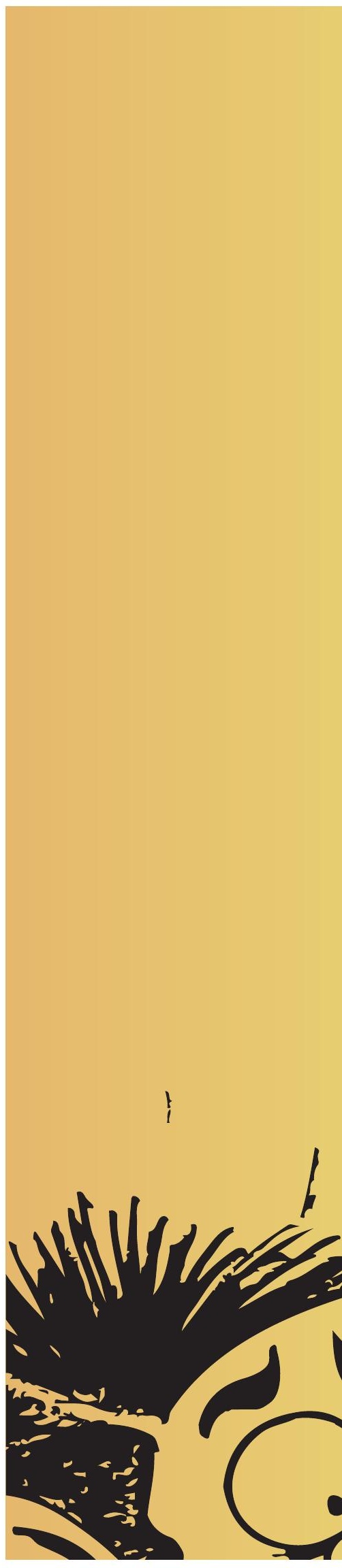


acción social, por cualquier medio y forma, en su propia lengua y con sus propios símbolos.

2. El acceso universal a las tecnologías de información y comunicación.

3. La creación de medios de comunicación social, y al acceso en igualdad de condiciones al uso de las frecuencias del espectro radioeléctrico para la gestión de estaciones de radio y televisión públicas, privadas y comunitarias, y a bandas libres para la explotación de redes inalámbricas.

4. El acceso y uso de todas las formas de comunicación visual, auditi$v a$, sensorial y a otras que permitan la inclusión de personas con discapacidad.

5. Integrar los espacios de participación previstos en la Constitución en el campo de la comunicación."

"Art. 18.- Todas las personas, en forma individual o colectiva tienen derecho a:

1. Buscar, recibir, intercambiar, producir y difundir información veraz, verificada, oportuna, contextualizada, plural, sin censura previa, acerca de los hechos, acontecimientos y procesos de interés general, y con responsabilidad ulterior."

Como puede observarse, la preocupación por la libertad de pensamiento y de información está presente en múltiples instrumentos internacionales, regionales y nacionales.

\section{La libertad de pensamiento y de expresión}

Presente en las normas internacionales e internas de la mayoría de los Estados, la libertad de pensamiento se relaciona íntimamente con la libertad de expresión y de opinión que tiene sus propias características.

Podría afirmarse que la libertad de pensamiento constituye un principio genérico que va materializándose en la libertad de opinión, de expresión, de información, de prensa, etc.

La libertad de pensamiento es un hecho. Aún cuando no existieran normas que la coarten, a nadie le estaría impedido pensar como a bien tuviera, mientras no exteriorice sus pensamientos. No es igual a la libertad de expresión que trae aparejada la transmisión externa de los pensamientos y sus consecuencias.

De otra parte, cuando nos referimos a la libertad de información estamos ante el derecho de los seres humanos para buscar, recibir y transmitir datos que alimenten esa curiosidad innata que tenemos. Cosa distinta es la libertad de prensa, que tiene especial importancia para la profesión del comunicador social.

En la década de los ochenta del siglo pasado la UNESCO propició un amplio debate sobre el rol de los medios de comunicación en la sociedad.

En la obra "Voces múltiples, un solo mundo" más comúnmente conocida como Informe Mac Bride, se afirma: "La comunicación sostiene y 
6. Mac Bride, Sean. Voices multiples un seul monde. Nouvelles editions africaines. UNESCO, París, Dakar, 1980. (Traducción libre) p. 3

7. Le Monde diplomatique. París, agosto de 2008. anima la vida. Motor y expresión de la actividad social y de la civilización, ella condujo al hombre y a los pueblos del instinto a la inspiración, a través de un conjunto de procesos y sistemas de información, de impulsión y control... Ella traduce el pensamiento en acto, y refleja todas las emociones y necesidades a partir de los gestos más simples, asegurando la continuidad de la vida hasta las manifestaciones supremas de la creación - o de la destrucción”. ${ }^{6}$

Por esa característica de traducir los pensamientos en actos, el riesgo de un uso inadecuado de la comunicación es permanente. La calumnia, la transmisión de datos que induzcan a la xenofobia, el delito, la intolerancia, la intromisión en la vida privada, el atentar contra la seguridad interna de un Estado, son algunas de las múltiples formas en que el uso de la comunicación social puede generar daño.

Para ello se han establecido límites en los propios instrumentos jurídicos, específicamente cuando se vulneran otros derechos, como el derecho a la intimidad personal o el honor.

Así, el artículo 19 de la Constitución prohíbe "la emisión de publicidad que induzca a la violencia, la discriminación, el racismo, la toxicomanía, el sexismo, la intolerancia religiosa o política y toda aquella que atente contra los derechos".

La errada concepción de algunos medios de comunicación o comunicadores que asumen el rol de fiscales o jueces supremos frente a los más diversos actos humanos, ha suscitado en el último tiempo una peligrosa reacción de ciertos gobiernos que puede conducirnos al otro extremo, pues se verían afectadas libertades que son propias de toda democracia.

Ya señalábamos antes que es tentación de todo totalitarismo frenar la libertad de expresión. Entonces, no cabe duda que, por los excesos de unos cuantos, sean vulnerados principios de derechos humanos que son conquistas de la humanidad y, sobre todo, de la razón.

Una reiterada crítica a ciertos medios de comunicación, particularmente televisivos, se refiere a la calidad de sus programas.

Pierre Jourde, profesor de la Universidad de Grenoble, en un artículo titulado "La máquina embrutecedora" señala: “...los medios han sabido dar dimensiones monstruosas a ese deseo universal de estupidez que duerme inclusive en el fondo del intelectual más elitista. Dicho fenómeno es capaz de destruir una sociedad, de volver ridículo todo esfuerzo político. ¿Para que esforzarse en reformar la escuela o la Universidad? El trabajo educativo es saqueado por la estupidez mediática, la bufonería erigida en medio de expresión, el despliegue de los valores del dinero, la apariencia y el individualismo estrecho que difunde la publicidad, última razón de ser de los grandes grupos mediáticos. Fealdad, agresividad, voyeurismo, vulgaridad, incultura, estupidez invitan al espectador a complacerse en una imagen infantilizada y degradada de si mismo, sin ambición de salir de sí, de su persona, de su medio, de su grupo, de sus "preferencias".

$\mathrm{Al}$ cuestionar con dureza a quienes dirigen los medios de televisión anota: "no siempre, o no solamente son unos imbéciles, son también malhechores. Admitimos que una comida o un aire viciados pueden ser nefastos para el cuerpo... (también)...existen representaciones que contaminan el espíritu".

Es verdad que se producen excesos en el manejo de determinados medios de comunicación, que se han convencido de ser el "cuarto poder del Estado", criterio que tendría que revisarse en el caso ecuatoriano, pues junto a las tradicionales funciones: ejecutiva, legislativa y judicial se han incorporado 
recientemente las de transparencia, electoral y de control social, lo cual haría que los medios no sean sino uno más de los tantos poderes que tenemos.

8 http://www.libertaddeexpresion.html

Sin embargo, las normas existentes deberían ser suficientes para frenar esos excesos.

Una sociedad con restricciones a la libertad de expresión no es democrática. Pero al mismo tiempo una sociedad que bajo el pretexto de dicha libertad privilegia la difusión de mensajes sesgados o embrutecedores, con el único sustento de tener el poder económico o político, tampoco lo es.

Como señala Noam Chomsky: "Si crees en la libertad de expresión entonces crees en la libertad de expresión para puntos de vista que te disgustan. Por ejemplo, Goebbels estaba a favor de la libertad de expresión para los puntos de vista que compartía, igualmente Stalin. Si estás a favor de la libertad de expresión, eso significa que estás a favor de la libertad de expresión precisamente para los puntos de vista que no compartes, de otra forma, no estarías a favor de la libertad de expresión." 